Journal of Clinical Investigation

Vol. 42, No. 7, 1963

\title{
TURNOVER RATE AND OXIDATION OF FREE FATTY ACIDS OF BLOOD PLASMA IN MAN DURING EXERCISE: STUDIES DURING CONTINUOUS INFUSION OF PALMITATE-1-C ${ }^{14} *$
}

\author{
By RICHARD J. HAVEL, ARNOLD NAIMARK, † AND CHRISTIAN F. BORCHGREVINK $\ddagger$ \\ (From the Cardiovascular Research Institute and the Department of Medicine, University of \\ California School of Medicine, San Francisco, Calif.)
}

(Submitted for publication December 28, 1962; accepted March 7, 1963)

Previous studies have shown that the free fatty acids (FFA) of blood plasma are renewed much more rapidly than the other plasma lipids (1-3). It has been calculated that, if oxidized, they could satisfy the requirements of oxidative metabolism in the postabsorptive state in man at rest (3). Measurements of arteriovenous (A-V) differences have shown that sufficient FFA are taken up by the heart in the postabsorptive state to account for much of its oxidative metabolism, provided they are all oxidized (4-5). Similar observations related to skeletal muscle have been difficult to evaluate because of the multiple sources of venous blood draining limbs (6). Measurements of radioactivity in expired $\mathrm{CO}_{2}$ after injection of $\mathrm{C}^{14}$-labeled fatty acids suggest that, in man (3) and in dogs (7), oxidation of circulating FFA accounts for 25 to $50 \%$ of energy metabolism in the postabsorptive state at rest. Such quantitative evaluations have been complicated by recycling of FFA between blood and tissues, recycling of triglyceride fatty acids from the liver, and slow equilibration of labeled $\mathrm{CO}_{2}$ derived from oxidation of labeled FFA with the body pool of $\mathrm{CO}_{2}$.

We thought that many of these problems could be minimized if such studies were done during exercise, since blood flow would be directed primarily to working muscle. Thus, steady-state conditions might be reached earlier and permit more reliable calculation of the contribution of plasma FFA to total body metabolism. Further-

* Supported by grants H-6285 and H-2554 from the U. S. Public Health Service, the Health Foundation of the Arrowhead Area, and the San Mateo County Heart Association, Calif.

$\dagger$ Junior Research Fellow, San Francisco Heart Association.

$\ddagger$ Lederle International Fellow, 1962 . more, since energy metabolism during exercise can be considered essentially that of skeletal muscle, such studies would measure utilization of FFA by muscle in vivo.

The efflux of FFA from plasma is increased during exercise (8-11), presumably a result of augmented blood flow to working muscles (1011). Basu, Passmore, and Strong (12) have shown that the concentration of FFA in plasma from antecubital veins is elevated when men walk 3 to 4 miles per hour for more than 30 to $60 \mathrm{~min}$ utes. This suggests that the turnover rate of FFA is considerably increased during such exercise. We have chosen this model for our studies. The results show that the turnover rate of FFA is indeed increased and strongly suggest that FFA are the major circulating metabolites burned by working muscle in the postabsorptive state.

\section{METHODS}

Experimental subjects and procedures. Six members of a wrestling team, aged 23 to 30 , volunteered as subjects. All were participating in a strenuous program of training and were in excellent physical condition. The nature and purpose of the study were explained to them in detail. They reported to the laboratory in the morning after fasting for 12 to 15 hours. Four received water as desired during the study. Two were first fed a fat-free breakfast containing $80 \mathrm{~g}$ of carbohydrate and $20 \mathrm{~g}$ of protein; and they also received $25 \mathrm{~g}$ of sucrose in the form of lemonade every half-hour during the study, so that their total intake of carbohydrate was $280 \mathrm{~g}$ in 5 hours. A brachial artery was cannulated by a modification of the technic of Bernéus, Carlsten, Holmgren, and Seldinger (13), and a catheter of the Rochester type was placed in an antecubital vein of the opposite arm. Physiological saline solution without heparin was used to maintain patency of the catheters. Expired air was collected intermittently through a low-resistance valve into a Tissot spirometer. End-tidal nitrogen and $\mathrm{CO}_{2}$ concentrations were measured continuously at the mouth in 
order to monitor respiratory exchange ratio by the method of Naimark, Wasserman, and Mcllroy (14). Heart rate was measured at the times of sampling by counting the radial pulse, or from electrocardiographic records. Samples of blood were taken during the same periods from the arterial catheter. When the catheters had been inserted and the subjects were resting comfortably in a chair, an infusion of palmitate-1- $\mathrm{C}^{\mathbf{1 4}}$ was started through the venous catheter at a constant rate of .13 to $.17 \mu \mathrm{c}$ per minute. The syringes used in the infusion pump were calibrated by weighing the water they delivered. After 1 hour, the subjects began to walk on a horizontal treadmill at a constant rate of 3 to 4 miles per hour for a period of 2 hours. They then resumed their seats and rested, two of the fasting subjects for a half-hour and all the others for an hour. The quantity of blood taken during the experiments was 4 to $5 \%$ of the blood volume. The subjects felt well and experienced little or no fatigue during the study. A seventh subject, who was not participating in a program of training, was studied in the same manner during a 4-hour period of rest after a fast of 12 hours.

Analytical methods. Samples of expired air were taken from the Tissot spirometer into rubber bags for measurement of $\mathrm{CO}_{2}$ and $\mathrm{C}^{14} \mathrm{O}_{2}$ by the method of Fredrickson and Ono (15). Expired air was also analyzed for $\mathrm{O}_{2}$ and $\mathrm{CO}_{2}$ with the Scholander apparatus, and the results were used to calculate $\mathrm{O}_{2}$ consumption, $\mathrm{CO}_{2}$ production, and respiratory exchange ratio. There was excellent agreement between the end-tidal and expired air estimates of respiratory exchange ratio. Blood samples for analysis of gas tensions were taken in heparinized syringes and analyzed promptly with Severinghaus electrodes (16). Blood samples for analysis of lactate were taken directly into chilled tubes and were immediately placed in ice. Serum was separated at $3^{\circ} \mathrm{C}$, and lactate was determined by the method of Loomis (17). Blood samples for other determinations were taken by syringe, transferred to heparinized tubes, and chilled in ice. A portion was taken for measurement of volume of packed red cells in Wintrobe tubes, and the remainder was centrifuged at $3^{\circ} \mathrm{C}$ within 2 hours of collection at $1,200 \times g$ for 20 minutes. Duplicate $2-\mathrm{ml}$ samples of plasma were taken for extraction of FFA in $10 \mathrm{ml}$ of Dole's mixture (18). For purifying the extract, the directions of Trout, Estes, and Friedberg (19) were followed. Three $\mathrm{ml}$ of the purified extract was titrated with thymol blue by the method of Dole (18). An excess of $0.02 \mathrm{~N}$ sodium hydroxide solution amounting to approximately the same volume used in the titration was added, and the two phases were mixed with the aid of a tube buzzer. The upper (heptane) phase was removed with a Pasteur pipette, and the lower (aqueous) phase extracted with an additional $3 \mathrm{ml}$ of heptane. These two extracts, which contained the neutral lipids, were combined. The aqueous phase was then acidified with $0.05 \mathrm{~N}$ hydrochloric acid solution and extracted three times with 3 $\mathrm{ml}$ of heptane as before to obtain the separated FFA. In the first study, the lipids of $2 \mathrm{ml}$ of plasma were also extracted in chloroform-methanol and separated into three fractions on silicic acid columns (20). The second fraction, which contained glycerides and FFA, was then separated by the solvent partition method of Borgström (21). Since the two methods gave virtually identical specific activities for FFA, the first and simpler method was used in all other studies. In studies continuing for longer periods, accumulation of radioactivity in phospholipids and cholesterol esters might make it necessary to use the second method. The extracts containing neutral lipids and FFA were evaporated, dissolved in toluene containing $0.3 \%$ diphenyloxazole, and counted in a Packard Tri-Carb liquid scintillation spectrometer to an accuracy of at least $2 \%$. When palmitic acid-1- $\mathrm{C}^{\mathbf{1 4}}$ was added to the original extraction mixture and carried through the analytical procedure, 92 to $96 \%$ was recovered in the separated FFA. The values for radioactivity in FFA were corrected accordingly. The plasma concentration of glucose was determined by a glucose oxidase method (22), glycerol by a modification of the enzymatic method of Wieland (23), and total proteins by a biuret method (24). Plasma volume was determined with $\mathrm{I}^{131}$-labeled human serum albumin.

Preparation of radioactive materials for injection. Palmitic acid-1-C ${ }^{14}$ with SA of $6 \mathrm{mc}$ per mmole ${ }^{1}$ and containing at least $99 \%$ palmitic acid by gas-liquid chromatography was complexed with human serum albumin as described previously (25) and diluted to a concentration of about $0.1 \mu \mathrm{c}$ of $\mathrm{C}^{14}$ and $10 \mathrm{mg}$ of albumin per $\mathrm{ml}$. $\mathrm{I}^{131}$-labeled human serum albumin was obtained commercially. ${ }^{2}$

Calculations. At rest, the plasma concentration of palmitate-1- $\mathrm{C}^{14}$ became virtually constant 10 minutes after starting the infusion. Since the disappearance of labeled palmitate follows first order kinetics, the fractional turnover rate was calculated from Equation 1 (26): $k=i / q$, where $k$ is the fractional turnover rate $\left(\min ^{-1}\right), i$ is the rate of infusion of palmitate-1-C $\mathrm{C}^{\mathbf{1 4}}$ (counts per minute and minute), and $q$ is the total radioactivity in plasma FFA (counts per minute and liter $\times$ plasma volume in liters). In the steady state, it also holds that $k=I / Q$ (Equation 2 ), where $I$ is the rate of influx of FFA into the plasma (millimoles per minute) and $Q$ is the plasma content of FFA (millimoles per liter $\times$ plasma volume in liters). Then: $I=i /(q / Q)=i / P$ (Equation 3 ), where $P$ is the specific activity of plasma FFA (counts per minute and millimole).

The turnover rate, $I$, of FFA was calculated in terms of carbon atoms, assuming a mean chain-length of 17 . The concentration and specific activity of FFA varied little during the second hour of exercise, so the values obtained 135, 150, 165, and 180 minutes after starting the infusion were averaged to obtain $q$ and $P$. The values at rest 45 and 60 minutes after stopping exercise, which also agreed closely, were used to obtain $q$ and $P$ at rest.

The fractional turnover rate of FFA is inversely related to $q$ (Equation 1). Changes in $i / q$ will be designated as changes in the rate of efflux of FFA from plasma.

${ }^{1}$ Research Specialties Co., Richmond, Calif.

2 Abbott Laboratories, North Chicago, Ill. 


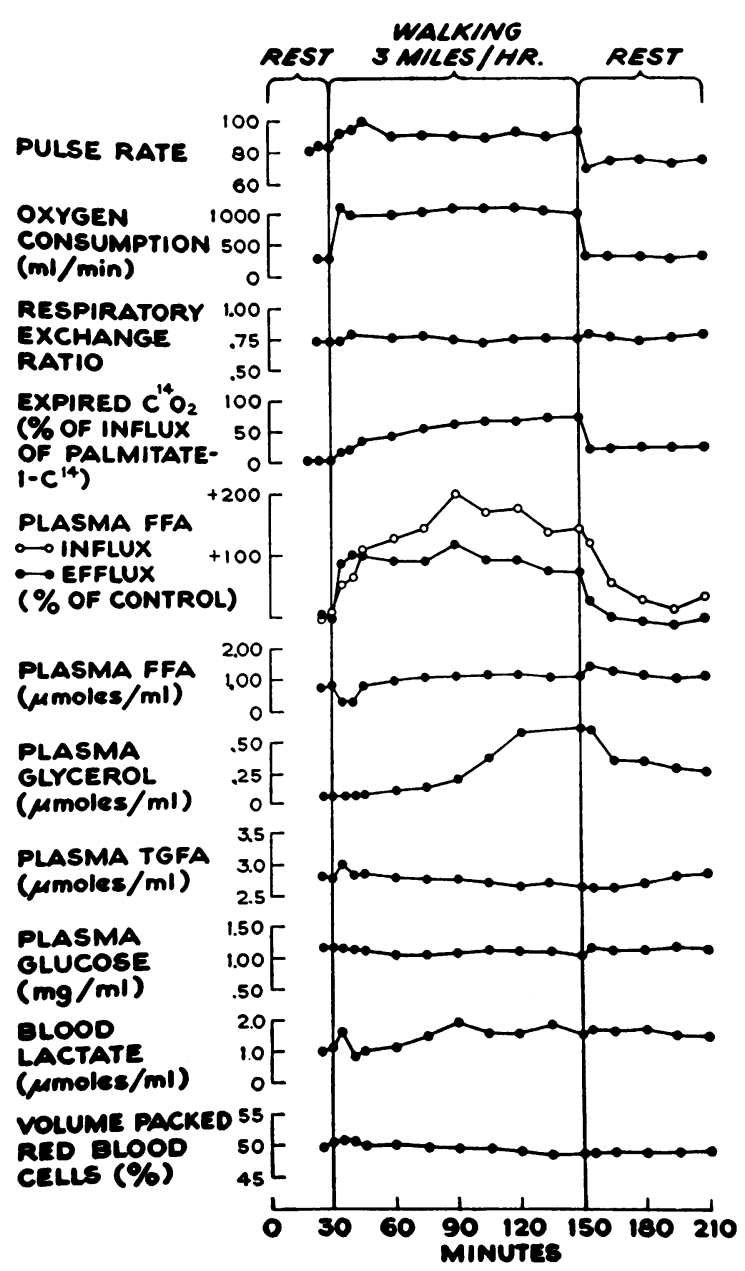

Fig. 1. DATA From a SINGLE EXPERIMENT IN A FASTING SUBJECT. Palmitate-1-C ${ }^{14}$ was injected intravenously at a constant rate throughout. In this study, unlike the others, the period of rest preceding exercise was only one-half hour. The changes in influx of plasma FFA are plotted from the reciprocals of the specific activity of plasma FFA at each interval of time, and the changes in efflux from the reciprocals of the radioactivity in FFA per unit volume of plasma (11).

The turnover rate of FFA is inversely related to $P$ (Equation 3). Changes in $i / P$ will be designated as changes in the rate of influx of FFA into the plasma.

The equation for calculation of the percentage of total $\mathrm{CO}_{2}$ production derived from rapid oxidation of circulating FFA was derived as follows: $\mathrm{CO}_{2}$ (FFA) $=17$ IF (Equation 4), where $\mathrm{CO}_{2}$ (FFA) is the rate of production of $\mathrm{CO}_{2}$ from the FFA pool (millimoles per minute), and $F$ is the fraction of FFA leaving the plasma pool which is rapidly oxidized. $\mathrm{CO}_{2}$ (total) $\times R=I P F$ (Equation 5), where $\mathrm{CO}_{2}$ (total) is the rate of production of $\mathrm{CO}_{2}$ (millimoles per minute) and $R$ is the specific activity of $\mathrm{CO}_{2}$ (counts per minute and millimole). $\%=$ $100 \mathrm{CO}_{2}$ (FFA) $/ \mathrm{CO}_{2}$ (total) (Equation 6). Substituting, $\%=\left[100 \times 17 \times I \times \mathrm{CO}_{2}\right.$ (total) $\left.\times R\right] /\left[I \times \mathrm{CO}_{2}\right.$ (total) $\times P]=1,700 R / P$ (Equation 7). Since $R$ increased only 2 to $8 \%$ during the second hour of exercise in these studies, the same periods of time were used to calculate $R$ as to calculate $P$.

\section{RESULTS}

Data obtained during one experiment in a fasting subject are shown in Figure 1. Pulse rate and oxygen consumption varied little during the exercise in this or any other subject. The rate of efflux of $\mathrm{C}^{14} \mathrm{O}_{2}$ increased rapidly during the first 30 minutes of exercise, but very little during the second hour. The rate of efflux of FFA from the plasma changed rapidly in relation to exercise and followed closely, in time, changes in oxygen consumption and pulse rate, whereas the rate of influx of FFA into the plasma changed more slowly. These differing time relationships accounted for the transient fall in the plasma concentration of FFA in the first few minutes of exercise, the subsequent gradual rise, and the rapid increase when exercise ceased. These changes in three of the four fasting subjects are clearly seen in Figure 2. In the two fed subjects, the values varied little during the experiments except for an increase after stopping exercise in one. Values for glucose, shown in Figure 2, fell slightly but consistently during exercise in the fasting subjects and more so in the fed. In the fasting sub-

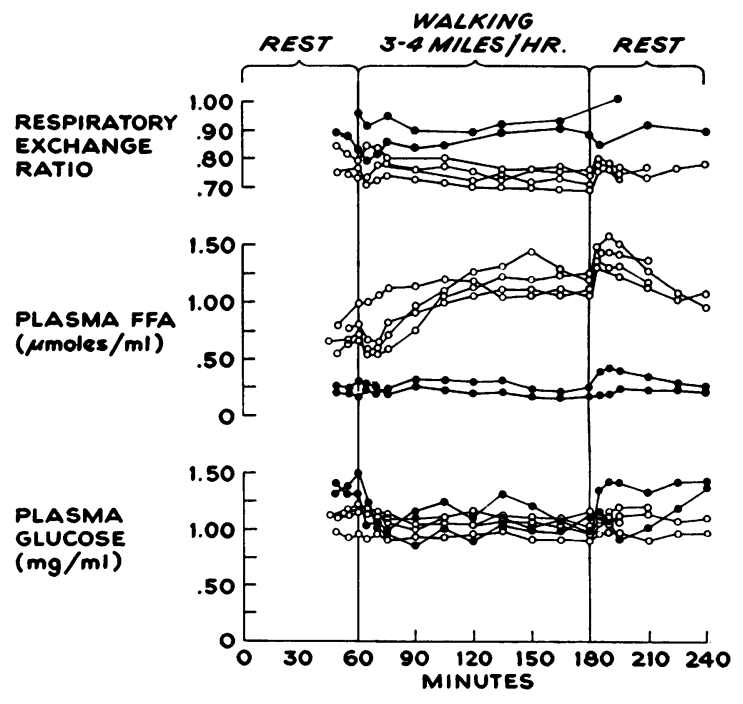

Fig. 2. INDIVIDUAL DATA FROM EACH OF SIX EXPERIments. Open circles: fasting subjects; closed circles: subjects fed carbohydrate. 
jects, the respiratory exchange ratios tended to be slightly lower during exercise than at rest.

Serum lactate concentration averaged 1.31 $\mu$ moles per $\mathrm{ml}$ (range, 0.95 to 1.64 ) at rest and $1.44 \mu$ moles per $\mathrm{ml}$ (range, 0.87 to 1.80 ) during the second hour of exercise in the fasting subjects. In the fed subjects, corresponding values were 3.24 to 6.10 and 1.72 to $4.53 \mu$ moles per $\mathrm{ml}$. Values for $\mathrm{pO}_{2}$ and $\mathrm{pCO}_{2}$ varied no more than 9 and $4 \mathrm{~mm} \mathrm{Hg}$, respectively, in any subject and did not change appreciably with exercise. Therefore, the values for the respiratory exchange ratio can be taken to reflect oxidative and synthetic reactions involved in cellular metabolism.

Plasma levels of glycerol increased gradually to a maximum of $0.54,0.65$, and $0.52 \mu$ mole per $\mathrm{ml}$ during the second hour of exercise in three of the fasting subjects (an example is shown in Figure 1). Values were not obtained in the others. The plasma concentration of triglyceride fatty acids varied little during the studies. The concentration of total protein in plasma and the packed volume of red cells usually fell slightly. but never more than 5\%. Heart rates at rest varied from 62 to 85 beats per minute, and during the second hour of exercise from 95 to 112 beats.

Data pertaining to the turnover rate and oxidation of FFA are summarized in Table I. The differences between oxidative metabolism in the postabsorptive and fed states are readily apparent. During exercise, the plasma concentrations of FFA in the fasting subjects were about six times greater and their turnover rate about four times greater than in the fed subjects. In no fasting subject, however, was the turnover rate sufficiently great to account for all oxidative metabolism, even if all the FFA were oxidized. Actually, 61 to $87 \%$ was oxidized, so that FFA transported in the blood accounted for slightly less than half of oxidative metabolism. At rest, the turnover rate of FFA carbon exceeded that of $\mathrm{CO}_{2}$, but since only about $20 \%$ was oxidized, the contribution of FFA to oxidative metabolism was only about half that observed during exercise. The data obtained at rest, however, did not represent steady-state conditions, since the specific activity of FFA rose during the hour after stopping exercise. The contribution of FFA to energy metabolism may, therefore, have been higher than indi- cated by our figures. In the subject who rested during the 4-hour period of study, the specific activity of $\mathrm{CO}_{2}$ increased 82,41 , and $12 \%$ in the second, third, and fourth hours, respectively. The fractional oxidation of FFA during the fourth hour was somewhat greater than in the other fasting subjects at rest, but the turnover rate of FFA was lower, so that rapid oxidation of FFA appeared to account for $18 \%$ of oxidative metabolism. Radioactivity in plasma FFA was $11 \%$ higher in the fourth hour than in the first hour of this study, which might be taken as evidence of some recycling of labeled palmitate.

The fractional turnover rates for plasma FFA were calculated to be 0.35 to 0.48 per minute in the fasting subjects during exercise and 0.18 to 0.21 at rest. In the fed subjects, the figures were 0.57 and 0.64 per minute during exercise and 0.27 and 0.33 at rest. The fractional oxidation of FFA did not differ significantly in the fasting and fed subjects during exercise and was only slightly lower in the fed subjects at rest. The smaller contribution of circulating FFA to oxidative metabolism in the fed subjects appeared to result, therefore, almost entirely from decreased influx of FFA into the blood.

\section{DISCUSSION}

These studies provided quantitative data regarding the turnover rate and oxidation of circulating FFA during exercise. Several factors may, however, limit the precision of our calculations. It has been assumed that the infused, labeled palmitate mixes with a homogeneous pool of FFA, for which it is a representative tracer. The use of albumin-bound, labeled FFA has been challenged recently by Bates and Olson (27). They feel that such a tracer gives values too high for the turnover rate of FFA. There is reason to suspect, however, that the method they used for measuring turnover rate gives values too low, since the plasma they injected contained most of the radioactivity in fatty acid esters rather than in FFA, and the chemical nature of their labeled FFA is not known. Dole and Rizack (28) measured the turnover rate by a third, nonisotopic method and found values similar to those obtained by rapid injection of albumin-bound tracer. The fractional turnover rates we calculated in the fasting subjects during exercise correspond to half-times of 


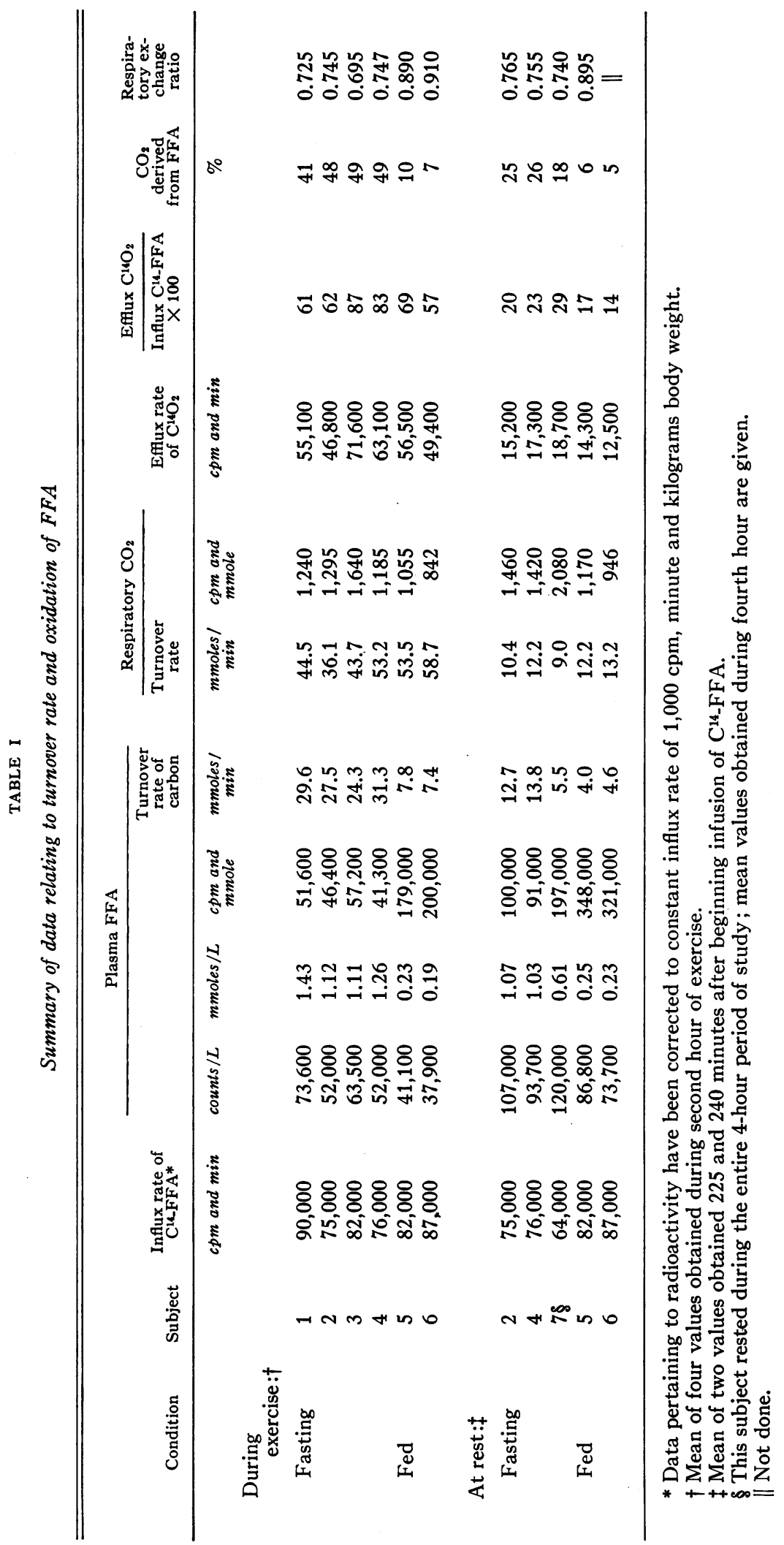


removal of 1.44 to 1.98 minutes, and in the fed subjects, 1.22 and 1.08 minutes. Friedberg, Harlan, Trout, and Estes (9) found that half-times of labeled palmitate during vigorous exercise averaged 1.46 minutes with the single-injection technic. $^{3}$ The question of the extent to which the metabolism of palmitate-1-C ${ }^{14}$ represents that of all circulating FFA has not been answered here. It is known, for example, that at rest linoleate turns over more rapidly than palmitate $(29,30)$. However, palmitate and oleate, which together comprise about $55 \%$ of circulating FFA (31), have similar turnover rates and are oxidized to a similar extent in resting, fasting subjects (3). In studies of oxidation of FFA, it is generally assumed that oxidation of the carboxyl carbon is equivalent to total oxidation of the molecule. This is based on the observation by Weinman and associates (32) that oxidation of palmitate labeled in the 1,6 , and 11 positions was similar when injected into rats in a tripalmitin emulsion. These observations have not been confirmed adequately for albumin-bound fatty acids. In a single comparison, Armstrong and associates ( 7 ) found similar oxidation of palmitate in the 1 and 6 positions after intravenous injection into dogs as the albumin complex.

The measurements made during the second hour of exercise provide good evidence that pertinent metabolic events had approached steady-state conditions. The cardiac output during such exercise should have been about $12 \mathrm{~L}$ per minute and splanchnic blood flow about $1 \mathrm{~L}$ per minute (33). Thus, the fraction of the cardiac output reaching the liver was only about one-third the value $(25 \%)$ found during rest (33). If, furthermore, the abdominal viscera did not increase their fractional extraction of FFA during exercise, splanchnic oxidation could contribute no more than $10 \%$ of the total oxidation of FFA. Recycling of FFA from liver as triglyceride fatty acids would also

${ }^{3}$ The single-injection method is preferable for determination of fractional turnover rate, since the volume of distribution of the isotope does not enter into the calculation. However, calculation of the turnover rate, which is a more important datum in our study, does require measurement of plasma volume and the assumption that this volume constitutes the FFA pool. In the method of continuous infusion, calculation of turnover rate does not depend on the volume of the compartment in which the isotope is distributed, and variations in the turnover rate are readily followed. be expected to decrease. The fraction of FFA entering adipose tissue would also be less if, as seems likely, a smaller fraction of the cardiac output perfused this tissue. Recycling of labeled FFA in the blood would then be expected to decrease. All these factors may have contributed to the constancy of the specific activity of FFA and almost steady production of $\mathrm{C}^{14} \mathrm{O}_{2}$ during the second hour of exercise. The slight increase in specific activity of $\mathrm{CO}_{2}$ that occurred may also have resulted from delayed oxidation of palmitate stored in tissue lipids. If so, our estimates of fractional oxidation of FFA may be somewhat high. On the other hand, lack of complete equilibration of $\mathrm{C}^{14} \mathrm{O}_{2}$ derived from oxidation of palmitate with body stores of bicarbonate would have an opposite effect.

The factors discussed here may limit the precision of our calculations, but it is unlikely that they can affect the conclusion that, in our fasting subjects, FFA were the chief fuel delivered to working skeletal muscle from the blood. This conclusion is probably generally applicable, but because of the highly selected nature of our subjects, studies of less well-trained individuals are needed.

These studies also show clearly that, during exercise, there is not only an increased rate of efflux of FFA from the blood, as shown previously (8-11), but also, as suggested by the studies of Basu and associates (12), an increased rate of influx into the blood as well, presumably from adipose tissue. Efflux doubled almost immediately, whereas influx increased slowly, so that the turnover rate of FFA increased gradually during the first hour of exercise. During this period, other metabolites must have made the major contribution to energy metabolism. During the second hour, the turnover rate of FFA was double and the turnover rate of $\mathrm{CO}_{2}$ four times that during the period of rest following the exercise. The contribution of FFA to energy metabolism, however, was twice as great during exercise because of the much higher rate of oxidation of FFA entering tissue cells. Whether muscle cells actually burned more of the FFA they received during exercise than at rest cannot be answered from our studies, although the data suggest that this is a possibility. In our studies, the concentration of FFA did not rise as much as in those of Basu and associates (12). These investigators inter- 
rupted the exercise to take samples of blood from an antecubital vein. Since the plasma level of FFA increases abruptly after stopping exercise because of a rapid fall in their fractional turnover rate (Figure 1) $(10,11)$ and venous blood levels may differ from arterial, the values they obtained do not reflect those in blood perfusing tissues during exercise.

The increased mobilization of FFA during exercise probably resulted from augmented hydrolysis of triglycerides in adipose tissue. This is supported by the rise in the plasma concentration of glycerol. Glycerol normally enters the blood from adipose tissue, as shown by its higher concentration in blood plasma from the saphenous vein than in that from an artery (34). Increases in the plasma level of glycerol during exercise have been found independently by Carlson, Ekelund, and Orö (35). Decreased esterification of fatty acids in adipose tissue would not, on the basis of current information (36), be expected to result in increased plasma levels of glycerol, whereas increased hydrolysis of triglycerides would. Other possible explanations for the increased concentration of glycerol in plasma during exercise include: 1) release from triglycerides hydrolyzed in working skeletal muscle (see below) and 2) decreased blood flow to the liver (33), which normally removes a large fraction of glycerol from the blood (34). Isotopic studies of glycerol turnover rate should clarify some of these questions.

Basu and co-workers (12) found increased plasma levels of FFA during exercise in adrenalectomized and hypophysectomized subjects comparable to those in healthy subjects and concluded that secretion of epinephrine and growth hormone could not account for mobilization of FFA. We suggest that mobilization of fatty acids during exercise may result from augmented activity of sympathetic nerves in adipose tissue with consequent local liberation of norepinephrine, a potent activator of triglyceride hydrolysis in this tissue (36). Infusions of norepinephrine cause mobilization and increased plasma levels of FFA (36), and have been reported recently to increase plasma levels of glycerol as well (37). Increased plasma concentrations of catecholamines, primarily norepinephrine, have been observed during exercise (38). Studies during conditions of decreased ac- tivity of the sympathetic nervous system should be rewarding in this connection.

The striking decrease in mobilization of FFA produced by glucose during exercise demonstrates once more the antagonism (11) between factors promoting and inhibiting release of FFA from adipose tissue. On the other hand, we were unable, in the two subjects studied, to find clear evidence of a glucose-sparing action on fatty acid oxidation in working muscle, since the fraction of FFA leaving the plasma compartment that was rapidly oxidized was not decreased by feeding the subjects carbohydrate. Such sparing of oxidation of injected FFA and triglyceride fatty acids in intact organisms $(20,39)$ and of FFA in eviscerated, diabetic rats (40) has been shown previously. Sparing of fatty acid oxidation by glucose has been observed in muscle preparations in vitro under some (41-43), but not all $(41,44,45)$ conditions, and esterification of fatty acids in this tissue appears to be increased by carbohydrate both in vivo (20) and in vitro $(43,45)$. The available evidence indicates, however, that carbohydrate inhibits mobilization of FFA from adipose tissue more readily than it inhibits their oxidation in other tissues (46). Our studies show that fewer FFA are burned in the fed state primarily because skeletal muscle receives less to burn.

The values for the respiratory exchange ratio suggest that in the postabsorptive state, fatty acids comprised almost all of the fuel of metabolism. Since less than half appeared to be derived immediately from circulating FFA, the question of alternate sources of fatty acids arises. Triglyceride fatty acids would appear to be the only other circulating source of fatty acids likely to be utilized by working muscle. The isolated, perfused rabbit heart can remove and oxidize triglyceride fatty acids contained in very low-density lipoproteins (47). From their relatively slow turnover rate, it seems unlikely, however, that triglyceride fatty acids can account for a large fraction of energy metabolism, particularly since, in the postabsorptive state, they must be synthesized in the liver from circulating FFA (25). Transport of ketoacids from liver to muscle is, for similar reasons, unlikely to supply more than a small fraction of energy requirements (46). These considerations suggest that the other important source of fatty acids for muscle metabolism must 
be within the muscles themselves. The mechanisms that increase mobilization of FFA from adipose tissue could also operate in relation to fat cells within muscle to release FFA; these could reach muscle cells by simple diffusion. Alternatively, as suggested by studies of Volk, Millington, and Weinhouse (48) and Neptune, Sudduth, Foreman, and Fash $(49,50)$, fatty acids derived from phospholipids and triglycerides within the muscle cells themselves might be utilized. Friedberg and Estes (51) have shown that palmitate-1$\mathrm{C}^{14}$ taken up in the resting forearm is oxidized over a prolonged period of time. This oxidation is greatly increased when the forearm muscles work.

In the fed state, the respiratory exchange ratios suggest that fatty acids comprised about onethird of the fuel of metabolism, although this measurement may be less reliable than in the postabsorptive state because of lipogenesis from carbohydrate. Approximately $10 \%$ was derived from oxidation of circulating FFA, suggesting that fatty acids from other sources were also being utilized in this condition.

\section{SUM MARY}

Palmitate-1- $\mathrm{C}^{14}$ was infused intravenously at a constant rate into healthy, young men for 4 hours. During the second and third hour, the subjects walked on a treadmill at 3 to 4 miles per hour. The specific activities of FFA of plasma and respiratory $\mathrm{CO}_{2}$ were measured at intervals. During the second hour of exercise, steady-state conditions were approached. From the data obtained. the turnover rate of FFA, the fraction of FFA rapidly oxidized, and the contribution of oxidation of circulating FFA to total energy metabolism have been calculated. During the second hour of exercise, the turnover rate of FFA carbon averaged 27.7 mmoles per minute in four subjects in the postabsorptive state and 7.6 mmoles per minute in two subjects who were fed carbohydrate in excess of their energy needs before and during the period of exercise. During the subsequent period of rest, the mean values were 13.3 and 4.3, respectively. Both fasting and fed subjects oxidized similar fractions of FFA entering tissues during exercise ( 57 to $87 \%$ ). At rest, the values were 20 to $23 \%$ for the fasting subjects and 14 to $17 \%$ for the fed subjects. Oxidation of FFA entering tissues accounted for 41 to $49 \%$ of energy metabolism during exercise in the fasting subjects and 7 to $10 \%$ in the fed subjects. Corresponding values at rest were 25 to $26 \%$ and 5 to $6 \%$. The results suggest strongly that in the postabsorptive state, FFA are the major fuel delivered to working muscle from the blood. Decreased mobilization of FFA after ingestion of carbohydrate seemed to account almost entirely for their decreased oxidation during muscular work.

The concentration of glycerol in the plasma increased markedly during exercise in fasting subjects. The mechanisms responsible for this change and for the increased mobilization of FFA during exercise are discussed in the light of available evidence.

\section{ACKNOWLEDGMENTS}

We wish to thank the members of the wrestling team of the Olympic Club of San Francisco who volunteered as subjects and Miss Joan Mayerle and Mrs. Agnes Frank for valuable technical help.

\section{REFERENCES}

1. Havel, R. J., and D. S. Fredrickson. The metabolism of chylomicra. I. The removal of palmitic acid1-C $\mathrm{C}^{14}$ labeled chylomicra from dog plasma. J. clin. Invest. 1956, 35, 1025.

2. Laurell, S. Turnover rate of unesterified fatty acids in human plasma. Acta physiol. scand. 1957, 41, 158.

3. Fredrickson, D. S., and R. S. Gordon, Jr. The metabolism of albumin-bound $\mathrm{C}^{\mathbf{1 4}}$-labeled unesterified fatty acids in normal human subjects. J. clin. Invest. 1958, 37, 1504.

4. Gordon, R. S., Jr., and A. Cherkes. Unesterified fatty acid in human blood plasma. J. clin. Invest. 1956, 35, 206.

5. Ballard, F. B., W. H. Danforth, S. Naegle, and R. J. Bing. Myocardial metabolism of fatty acids. J. clin. Invest. 1960, 39, 717.

6. Baltzan, M. A., R. Andres, G. Cader, and K. L. Zierler. Heterogeneity of forearm metabolism with special reference to free fatty acids. J. clin. Invest. 1962, 41, 116.

7. Armstrong, D. T., R. Steele, N. Altszuler, A. Dunn, J. S. Bishop, and R. C. De Bodo. Regulation of plasma free fatty acid turnover. Amer. J. Physiol. 1961, 201, 9.

8. Carlson, L. A., and B. Pernow. Studies on blood lipids during exercise. I. Arterial and venous plasma concentrations of unesterified fatty acids. J. Lab. clin. Med. 1959, 53, 833. 
9. Friedberg, S. J., W. R. Harlan, Jr., D. L. Trout, and E. H. Estes, Jr. The effect of exercise on the concentration and turnover of plasma nonesterified fatty acids. J. clin. Invest. 1960, 39, 215.

10. Carlson, L. A., and B. Pernow. Studies on blood lipids during exercise. II. The arterial plasmafree fatty acid concentration during and after exercise and its regulation. J. Lab. clin. Med. 1961, 58, 673.

11. Havel, R. J. Transport of fatty acids between adipose tissue and blood. Role of catecholamines and the sympathetic nervous system in Proc. First int. Pharmacol. Meeting, Stockholm, Sweden, 1961. London, Pergamon Press, 1963.

12. Basu, A., R. Passmore, and J. A. Strong. The effect of exercise on the level of non-esterified fatty acids in the blood. Quart. J. exp. Physiol. 1960, 45, 312.

13. Bernéus, B., A. Carlsten, A. Holmgren, and S. I. Seldinger. Percutaneous catheterization of peripheral arteries as a method for blood sampling. Scand. J. clin. Lab. Invest. 1954, 6, 217.

14. Naimark, A., K. Wasserman, and M. B. McIlroy. A new test of the adequacy of the cardiovascular response to exercise. Clin. Res. 1962, 10, 102.

15. Fredrickson, D. S., and K. Ono. An improved technique for assay of $\mathrm{C}^{14} \mathrm{O}_{2}$ in expired air using the liquid scintillation counter. J. Lab. clin. Med. 1958, 51, 147.

16. Severinghaus, J. W., and A. F. Bradley. Electrodes for blood $\mathrm{pO}_{2}$ and $\mathrm{pCO}_{2}$ determination. J. appl. Physiol. 1958, 13, 515.

17. Loomis, M. E. An enzymatic fluorometric method for the determination of lactic acid in serum. J. Lab. clin. Med. 1961, 57, 966.

18. Dole, V. P. A relation between non-esterified fatty acids in plasma and the metabolism of glucose. J. clin. Invest. 1956, 35, 150.

19. Trout, D. L., E. H. Estes, Jr., and S. J. Friedberg. Titration of free fatty acids of plasma: a study of current methods and a new modification. J. Lipid Res. 1960, 1, 199.

20. Havel, R. J., J. M. Felts, and C. M. Van Duyne. Formation and fate of endogenous triglycerides in blood plasma of rabbits. J. Lipid Res. 1962, 3, 297.

21. Borgström, B. Investigation on lipid separation methods. Separation of cholesterol esters, glycerides and free fatty acids. Acta physiol. scand. 1952, 25, 111.

22. Saifer, A., and S. Gerstenfeld. The photometric microdetermination of blood glucose with glucose oxidase. J. Lab. clin. Med. 1958, 51, 448.

23. Wieland, O. Eine enzymatische Methode zur Bestimmung von Glycerin. Biochem. Z. 1957, 329, 313.

24. Gornall, A. G., C. J. Bardawill, and M. M. David. Determination of serum proteins by means of the biuret reaction. J. biol. Chem. 1949, 177, 751.

25. Havel, R. J. Conversion of plasma free fatty acids into triglycerides of plasma lipoprotein fractions in man. Metabolism 1961, 10, 1031.
26. Solomon, A. K. The kinetics of biological processes. Special problems connected with the use of tracers. Advanc. biol. med. Phys. 1953, 3, 65.

27. Bates, M. W., and R. E. Olson. Turnover rates of plasma nonesterified fatty acids in the post absorptive dog (abstract). Fed. Proc. 1960, 19, 230.

28. Dole, V. P., and M. A. Rizack. On the turnover of long-chain fatty acids in plasma. J. Lipid Res. 1961, 2, 90.

29. Dustin, J-P., D. S. Fredrickson, P. Laudat, and K. Ono. Simultaneous comparison in vivo of removal rates of fatty acids from dog plasma (abstract). Fed. Proc. 1961, 20, 270.

30. Nestel, P. J., A. Bezman, and R. J. Havel. Metabolism of palmitate and linoleate in intact dogs. Amer. J. Physiol. 1962, 203, 914.

31. Dole, V. P., A. T. James, J. P. W. Webb, M. A. Rizack, and M. F. Sturman. The fatty acid patterns of plasma lipids during alimentary lipemia. J. clin. Invest. 1959, 38, 1544.

32. Weinman, E. O., I. L. Chaikoff, W. G. Dauben, M. Gee, and C. Entenman. Relative rates of conversion of the various carbon atoms of palmitic acid to carbon dioxide by the intact rat. J. biol. Chem. 1950, 184, 735.

33. Wade, O. L., and J. M. Bishop. Cardiac Output and Regional Blood Flow. Oxford, Blackwell Scientific Publications, 1962, chap. 6.

34. Borchgrevink, C. F., and R. J. Havel. Unpublished data.

35. Carlson, L. A., L. G. Ekelund, and L. Orö. Studies on blood lipids during exercise. IV. Arterial concentration of free fatty acids and glycerol during and after long time exercise in normal men. J. Lab. clin. Med. In press.

36. Havel, R. J. Catecholamines in Lipid Pharmacology. New York, Academic Press. In press.

37. Hagen, J. H., and P. B. Hagen. An enzymic method for the estimation of glycerol in blood and its use to determine the effect of noradrenaline on the concentration of glycerol in blood. Canad. J. Biochem. 1962, 40, 1129.

38. Vendsalu, A. Studies on adrenaline and noradrenaline in human plasma. Acta physiol. scand. 1960, 49 (suppl. 173), 1-123.

39. Fredrickson, D. S., and R. S. Gordon, Jr. Transport of fatty acids. Physiol. Rev. 1958, 38, 585.

40. Lossow, W. J., R. Hill, A. W. Soss, and I. L. Chaikoff. Extrahepatic oxidation of albumin-bound palmitic acid in the diabetic rat: its regulation by insulin. Arch. Biochem. 1958, 78, 288.

41. Fritz, I. B., and E. Kaplan. Effects of glucose on fatty acid oxidation by diaphragms from normal and alloxan-diabetic fed and starved rats. Amer. J. Physiol. 1960, 198, 39.

42. Schwartzman, L. I., and J. Brown. Glucose inhibition of fatty acid oxidation by rat diaphragm. Amer. J. Physiol. 1960, 199, 235. 
43. Fritz, I. B., and E. Kaplan. Effects of glucose on palmitate esterification by isolated rat diaphragms. Amer. J. Physiol. 1961, 200, 1047.

44. Fritz, I. B., D. G. Davis, R. H. Holtrop, and H. Dundee. Fatty acid oxidation by skeletal muscle during rest and activity. Amer. J. Physiol. 1958, 194, 379.

45. Eaton, P., and D. Steinberg. Effects of medium fatty acid concentration, epinephrine, and glucose on palmitate-1- $\mathrm{C}^{\mathbf{1 4}}$ oxidation and incorporation into neutral lipids by skeletal muscle in vitro. J. Lipid Res. 1961, 2, 376.

46. Fritz, I. B. Factors influencing the rates of longchain fatty acid oxidation and synthesis in mammalian systems. Physiol. Rev. 1961, 41, 52.

47. Gousios, A., J. M. Felts, and R. J. Havel. The metabolism of serum triglycerides and free fatty acids by the myocardium. Metabolism 1963, 12, 75.

48. Volk, M. E., R. H. Millington, and S. Weinhouse. Oxidation of endogenous fatty acids by rat tissues in vitro. J. biol. Chem. 1952, 195, 493.

49. Neptune, E. M., Jr., H. C. Sudduth, and D. R. Foreman. Labile fatty acids of rat diaphragm muscle and their possible role as the major endogenous substrate for maintenance of respiration. J. biol. Chem. 1959, 234, 1659.

50. Neptune, E. M., Jr., H. C. Sudduth, D. R. Foreman, and F. J. Fash. Phospholipid and triglyceride metabolism of excised rat diaphragm and the role of these lipids in fatty acid uptake and oxidation. J. Lipid Res. 1960, 1, 229.

51. Friedberg, S. J., and E. H. Estes, Jr. Direct evidence for the oxidation of free fatty acids by peripheral tissues. J. clin. Invest. 1962, 41, 677. 